\title{
Coronavirus: el enemigo invisible en la saliva
}

\section{Coronavirus: the invisible enemy in saliva}

Nos encontramos atravesando una crisis humanitaria sin precedentes en la historia la humanidad, en poco de más de un año, con más 3.5 millones de personas fallecidas, con poblaciones aisladas, nuestro estilo de vida cambió, y todo por una microrganismo que nos puso a reflexionar que el ser humano, no es invencible.

El manejo sanitario para el control y solución de la pandemia es tan diverso, que para los países que apostaron por la "ATENCION PRIMARIA DE LA SALUD", como concepto clave, tuvieron una mejor performance, los resultados en número de fallecidos, contagiados y también en la socio economía lo demuestran así; mientras para los países que apostamos por la estrategia hospitalaria únicamente, los resultados son desastrosos, Perú está entre los países con el mayor número de fallecidos por población a la fecha y una economía venida a menos.

Esto nos pone a reflexionar, que hicimos mal para llegar a esta situación, y lo primero que llama la atención, es que no se tomó en cuenta la evidencia científica, desarrollo tecnológico e información confiable y disponible, para tomar decisiones en materia de política sanitaria, el desarrollo científico de los últimos siglos es innegable en la reducción masiva de las epidemias en los siglos pasados, pero los conceptos y paradigmas cambian, y no podíamos aplicar al siglo XXI los mismos, debemos reconocer que, "lo único absoluto en ciencia, es que todo es relativo", el manejo sanitario adecuado de la pandemia covid-19 requiere innovación en base a conocimiento científico actual, y es por ello que en un modelo de "atención Primaria de la salud de los años 70", era fundamental reconocer la particularidad del Sars-cov2, y el diagnóstico oportuno con pruebas moleculares que pertenecen a institutos especializados debían dar soporte fundamental a esta estrategia de atención primaria de la salud.

Los conceptos claves de bioseguridad y conocimiento de transmisión de contagios, deben tener evidencia científica valida, para dar propuestas de solución, y en ello el Odontólogo tiene un papel fundamental, acaso por ser el profesional de la salud, que más experiencia diaria tiene en el control efectivo del aerosol microbiológico como efecto negativo y la bioseguridad como parte de actividad clínica, es por ello que el aporte para el control efectivo desde la odontología, debe ser tomada en cuenta en base a experiencia de desarrollo e innovación en las ultimas 3 a 4 décadas.

Como parte de la "atención primaria de la Salud", la vigilancia epidemiológica es fundamental está conformada por el diagnóstico oportuno (test moleculares), aislamiento y rastreo de contactos (inteligencia 
sanitaria), y ahora la tan anhelada vacuna contra el covid-19, que los resultados al día de hoy muestran que hay países que están recobrando su normalidad, con vacunas seguras y eficaces, y también son el nuevo paradigma en inmunizaciones, el ARNm, esta tecnología que tiene un desarrollo de 20 años aproximadamente, en su inicio sobre todo para tratamiento y prevención de algunos tipos de cáncer, en la pandemia con el Sars- Cov2, demostró que no solo se podía desarrollar una nueva vacuna en un tiempo record histórico, sino también no solo evitar desarrollo de enfermedad y muertes, sino también, según los últimos estudios, evitar transmisión de contagio, y esto si es un nuevo hito en los programas de inmunización de acá a futuro.

Hoy tenemos luz para salir de esta crisis, debemos buscar estar en el camino correcto para llegar lo más pronto posible a la misma, porque cada día de retraso significan perder miles de vidas, y eso es posible evitar gracias al desarrollo de la ciencia e innovación.

Omar Neyra Colchado ${ }^{1}$ 